\title{
Anemia of Chronic Kidney Disease: Pattern, Prevalence and Clinical Correlates. A Single Center Cross Sectional Study in South Western Nigeria
}

\author{
Uduagbamen $\mathrm{PK}^{1}$, Oyelese $\mathrm{AT}^{3}$, Alalade $\mathrm{BA}^{2}$, Ogunkoya $\mathrm{JO}^{4}$, Adesuyi $\mathrm{YO}^{1}$, \\ Timothy $\mathbf{O R}^{1}$ \\ ${ }^{1}$ Division of Nephrology and Hypertension, Department of Internal Medicine, Ben Carson (Snr) School of \\ Medicine, Babcock University/Babcock University Teaching Hospital, Ilishan-Remo, Nigeria. \\ ${ }^{2}$ Department of Hematology and Blood Transfusion, Ben Carson (Snr) School of Medicine, Babcock \\ University/Babcock University Teaching Hospital, Ilishan-Remo, Nigeria \\ ${ }^{3}$ Endocrine, Diabetes and Metabolism Unit, Department of Internal Medicine, Federal Medical Centre, \\ Abeokuta, Nigeria \\ ${ }^{4}$ Pulmonology Unit, Department of Internal Medicine, Ben Carson (Snr) School of Medicine, Babcock \\ University/Babcock University Teaching Hospital, Ilishan-Remo, Nigeria.
}

Corresponding Author: Peter K. Uduagbamen

\begin{abstract}
Introduction: Anemia is a modifiable and very common complication of chronic kidney disease that could be difficult to manage, more so in low income settings due to late recognition, and cost of undergoing required investigations and treatment.

Methods: A cross sectional study in which participants with chronic kidney disease and with glomerular filtration rate (GFR) $<60 \mathrm{ml} / \mathrm{min}$ had urine, blood and radiological investigations to determine albuminuria, GFR with electrolytes concentrations kidney length respectively.

Results: One hundred and forty four ( 82 males and 62 females) cohorts participated. The mean age of all participants was $48.76 \pm 15.87$ years. Only cohorts in stage 5 CKD were receiving ESAs, and of the 22, $19(86.3 \%)$ had anemia. The 45-59 years group had the highest blood pressure. A greater proportion of the participants had hypertension as the cause of CKD.

The prevalence of anemia was $39.58 \%, 37.80 \%$ in males and $41.93 \%$ in females. The mean hemoglobin concentration for cohorts was $10.96 \pm 1.85 \mathrm{~g} / \mathrm{dL}$, and was higher in males, $\mathrm{P}=0.06$, and was least with chronic interstitial nephritis. Metabolic acidosis was commoner in females, $\mathrm{P}=0.04$. Calcium Phosphate product was elevated in $10.5 \%$ of the participants. The mean serum creatinine was higher in males than females, $\mathrm{P}=0.001$. The mean eGFR and urine ACR were higher in males, $\mathrm{P}=0.02, \mathrm{P}=1.1$. The severity of anemia was positively related to stage of $\mathrm{CKD}$, $\mathrm{P}<0.001$.

Conclusion: Anemia complicating CKD is common, with a prevalence of $39.58 \%$ in our study. It was commoner in females, aged and elevated urine ACR and was negatively correlated with serum albumin. Determinants of renal anemia were age, and kidney function while predictors were increasing age, stage $5 \mathrm{CKD}$ and urine ACR. Improvement in kidney function, frequent reviews of red cell indices and medications are needed to minimize complications of renal anemia.
\end{abstract}

Keywords: anemia, chronic kidney disease, erythropoiesis stimulating agents, hemoglobin concentration

\section{INTRODUCTION}

Anemia as a complication and a modifiable risk factor in chronic kidney disease (CKD), is highly prevalent and is associated with CKD progression and the occurrence of adverse effects of the disease 
particularly cardiovascular disease and events. ${ }^{1}$ Renal anemia in addition to several pathophysiologic mechanisms, primarily results from reduced erythropoietin release from renal peritubular interstitium. ${ }^{2}$ Anemia correction alleviates the symptoms of disease, as in long term outcome with improvement in cognition and cardiac function, with declining rates of cardiac enlargement and left ventricular hypertrophy, thereby reducing length of hospitalization and, even death. Several factors are implicated in the progression of anemia in CKD including gender differences, infections and the use of inhibitors of the renin angiotensin aldosterone system (RAAS). ${ }^{3}$

A negative relationship exist between the severity of anemia and kidney function, a progressive decline in the hemoglobin concentration (HBC) is commonly seen in CKD from stage 2 disease. ${ }^{2}$ While androgens are known to play some stimulating effects on erythropoiesis, females are reported to experience delay in the commencement of this hematocrit decline. ${ }^{4}$ The ideal HBC in predialysis CKD is still debatable. While it a known fact that the use of ESAs are associated with improvement in many features associated with CKD, HBC $>13.0 \mathrm{~g} / \mathrm{dL}$ they have been reported to increase the risk of thrombotic events and mortality. ${ }^{5}$ Recent findings have found no significant adverse effects of using ESAs in person with $\mathrm{HBC}$ greater than $9 \mathrm{~g} / \mathrm{dL}^{6}$ Several guidelines have recommended a $\mathrm{HBC}$ of $<13 \mathrm{~g} / \mathrm{dL}$ as the treatment target in peridialysis CKD. ${ }^{7}$

Though modifiable, anemia correction could be cumbersome due to delayed diagnosis and suboptimal treatment strategies. ${ }^{7}$ In low and medium income nations (LMINs), the correction of anemia is even more cumbersome due to the high cost of diagnostic tests, poor availability of ESAs on account of cost, low educational attainment, cultural biases particularly against women, and the poor health financing by governments, private sector, multinational organization and philanthropists. ${ }^{8-10}$ Other contributing factors to the prevalence of anemia in CKD are inflammatory state associated with the release of anorexic cytokines coupled with intestinal congestion leading to poor digestion and absorption of nutrients, infections that comes with increased hemolysis, worsening proteinuria and acute depreciation of kidney function. Poor blood pressure control resulting in chronic elevation of intraglomerular, and peritubular capillaries which could alter renal perfusion pressures. ${ }^{10}$

It is reported that the rate of hemoglobin decline in CKD is faster in the early stages of the disease. ${ }^{4}$ Considering the adverse effects of anemia on the quality of life (QOL) and mortality in CKD patients, it therefore becomes very imperative that a deeper insight is needed more so in LINs, that will enable nephrologists to offer a better management of anemia from the early stages of CKD. Anemia in CKD is well reported in the advanced nations, and recent studies have revealed an increasing depth of knowledge concerning the epidemiology, correlates and management of anemia. ${ }^{11}$ In LMINs where anemia in CKD is expectedly more prevalent, literature is scares concerning anemia and its associates in CKD. We studied anemia in predialysis CKD and assessed its determinants, pattern, prevalence and clinical correlates in Nigeria as way of bridging the knowledge gap.

\section{MATERIALS AND METHODS}

This was a single center, cross sectional study conducted between August 2019 and July 2021 at the Nephrology and Hypertension clinic of Babcock University Teaching Hospital in Nigeria where between thirty and forty patients are seen weekly. One hundred and forty four participants (82 males and 62 females), 16 years or older, receiving regular nephrology consultation and had estimated glomerular filtration rate (eGFR) $<60 \mathrm{ml} / \mathrm{min}$ and were classified as having CKD according to KDOQI 2012 criteria, $^{12}$ were studied. 
Participants that met study inclusion criteria and gave informed consent were consecutively recruited. Data was taken from history, physical examination, laboratory and radiological findings and from participants' case file, and entered into a standard data form. Variables retrieved included sociodemographics, risk factors and etiology of CKD.

The height in meters $(\mathrm{m})$ and weight in kilogram $(\mathrm{kg})$ were measured using standard protocol and the body mass index (BMI) was calculated as $\mathrm{kg} / \mathrm{m}^{2}$. The blood pressure was taken in the sitting position with arm and back rested on a support, after five minutes of rest. Fresh urine samples were taken for Dip strip analysis with Combi 10 strips, and microalbuminuria testing with micral albustic strips. Blood samples were taken to determine the serum electrolytes, urea creatinine, albumin, full blood count, erythrocyte sedimentation rate. The kidney length from the RUS were also retrieved. The eGFR was estimated using the chronic kidney disease epidemiological collaboration (CKD-EPI) formula. ${ }^{13}$

The micra strip was taken from its container (which was closed immediately) and the end with the strip pad was immersed into the urine in the universal bottle to cover the full length of the strip pads for 50 seconds and remove by rolling it against the edge of the universal bottle to remove excess urine. The strip pad color was now matched against the "strip pad color" inscribed on the strip container and the results were documented. ${ }^{14}$ The combi 10 dip strip was taken from the container and the end containing the pad was immersed into the urine to cover the strip pad and remove after 60 seconds by rolling it against the edge of the universal bottle to remove excess urine.

This study was approved by the Babcock University Human Research Ethics Committee (BUHREC) of Babcock University (NHREC/24/01/2018 and BUHREC501/19) and study protocol was in accordance with the tenets Helsinki declaration of 1973 (revised in 2000). ${ }^{15}$

\section{Definitions}

The etiological diagnosis of CKD in this study was not biopsy based, therefore,

Hypertension associated CKD was defined as kidney disease cause by long standing hypertension, more prevalent in the elderly and late middle age and,

Chronic glomerulonephritis was defined as kidney disease complicated by hypertension, more prevalent in the young and early middle age with or without antecedent history of pharyngitis or skin sepsis.

Chronic interstitial nephritis was defined as kidney disease resulting from a significant exposure to exogenous nephrotoxins, after ruling out

Hypertension: Blood pressure $\geq 140 / 90$ $\mathrm{mmHg}^{.16}$

Diabetes: Confirmed diagnosis, fasting blood sugar (FBS) $\geq 126 \mathrm{mg} / \mathrm{dL}$, use of antidiabetic drugs. ${ }^{17}$

Anemia: Hemoglobin concentration $<13$ $\mathrm{mg} / \mathrm{dL}$ in males, and $<12 \mathrm{mg} / \mathrm{dL}$ in females

Hypoalbuminemia: serum albumin $<35 \mathrm{mg} / \mathrm{dL}^{19}$

Metabolic acidosis (MA): serum bicarbonate $<22 \mathrm{mmol} / \mathrm{L}^{20}$

Microalbuminuria: Urine ACR $>3.4 \mathrm{mg} / \mathrm{mmoL}^{21}$

Proteinuria: dip strip protein $\geq 1+{ }^{22}$

Dyslipidaemia: Total cholesterol $\geq 6.21 \mathrm{mmol} / \mathrm{L}^{23}$

Low-density lipoprotein cholesterol $(\mathrm{LDL})>4.14 \mathrm{mmol} / \mathrm{L} .^{23}$

High-density lipoprotein cholesterol (HDL) $<1.03 \mathrm{mmol} / \mathrm{L}^{23}$

Triglycerides $\geq 1.69 \mathrm{mmol} / \mathrm{L}^{23}$

Shrunken kidneys: Length $<9 \mathrm{~cm} .{ }^{24}$

Data analysis was with SSPS.

Continuous variables, presented as mean with standard deviation, were compared using student's t-test while categorical variables, presented as proportions and frequencies, were compared using Chisquare or fisher's exact test. The P-value $<0.05$ was considered statistically significant. Variables with $p<0.025$ from the univariate model were included as 
Uduagbamen PK et.al. Anemia of chronic kidney disease: pattern, prevalence and clinical correlates. a single center cross sectional study in South Western Nigeria.

adjustment variables in multivariate analyses to determine independent predictors of anemia in CKD. ${ }^{25}$

\section{RESULTS}

One hundred and forty four cohorts (82 males and 62 females) participated. The mean age of all participants was 48.76 \pm 15.87 years. The proportion of the females $\geq 60$ years was higher compared to the males, $\mathrm{P}=0.003$. Thirty three $(22.92 \%)$ of the CKD cohort had stage $3 \mathrm{a}$ disease, 47 $(32.63 \%)$ in stage 3b, $42(29.17 \%)$ in stage 4, $22(15.28 \%)$ in stage 5 (non-dialytic). Eighty eight $(61.1 \%)$ of participants were receiving either an angiotensin converting enzyme inhibitors (ACEI) or an angiotensin receptor blocker (ARB), majority of these were middle aged or elderly, and males. Only cohorts in stage 5 CKD were receiving ESAs, and of the 22, $19(86.3 \%)$ had anemia. The mean BMI of all cohorts, males and females were $26.53 \pm 4.51 \mathrm{~kg} / \mathrm{m}^{2}, 26.64 \pm 4.26 \mathrm{~kg} / \mathrm{m}^{2}$ and $26.39 \pm 4.85 \mathrm{~kg} / \mathrm{m}^{2}, \mathrm{P}=0.8$. A greater proportion of the women compared to males had normal SBP $(70.97 \%$ versus $54.88 \%)$ and DBP $(80.64 \%$ versus $68.29 \%$ ) respectively. The $16-29$ and the 45-59 years age groups had the lowest and the highest systolic and diastolic BP respectively.

Table 1: Sociodemographic and clinical characteristics of participants

\begin{tabular}{|l|l|l|}
\hline Variables & Frequency & Percentage \\
\hline Sex & & \\
Males & 82 & 56.94 \\
Females & 62 & 43.06 \\
\hline Age, years & & \\
$16-29$ & 16 & 11.11 \\
$30-44$ & 40 & 27.78 \\
$45-59$ & 62 & 43.06 \\
$60-74$ & 19 & 13.20 \\
$>75$ & 9 & 6.25 \\
\hline BMI, kg/m & & \\
$<25.00$ & 58 & 40.28 \\
$>25.00$ & 86 & 59.72 \\
\hline SBP, $\mathbf{m m H g}$ & & \\
$<140$ & 89 & 61.81 \\
$>140$ & 55 & 38.19 \\
\hline DBP, $\mathbf{m m H g}$ & & \\
$<90$ & 106 & 73.61 \\
$>90$ & 38 & 26.39 \\
\hline
\end{tabular}

A greater proportion of the participants had hypertension as the cause of CKD (Figure 1). This was jointly followed by chronic interstitial nephritis (19.4\%) and CGN (19.4\%). Majority (78.6\%) of participants with CIN had NSAIDs associate kidney disease.

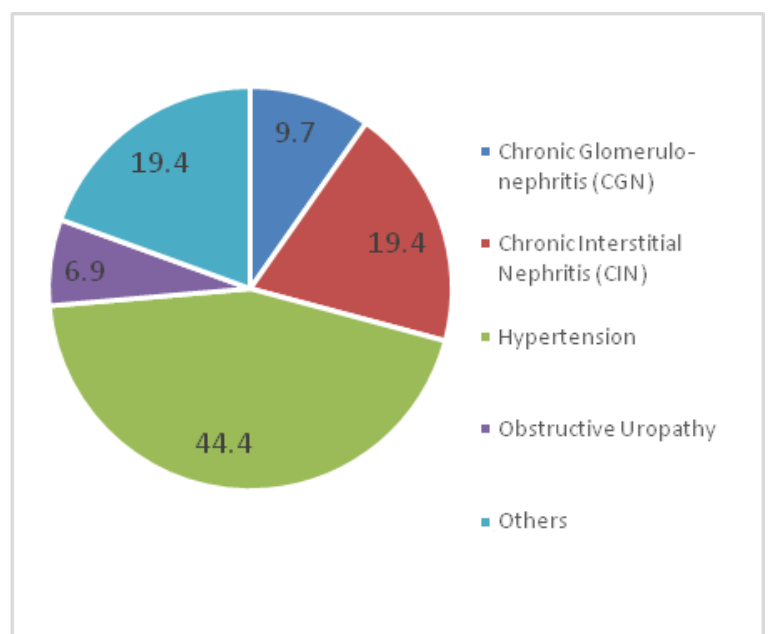

Figure 1: Pie chart showing the etiologies of CKD in the participants

Anemia was found in $39.58 \%$ of all participants, $37.80 \%$ in males and $41.93 \%$ in females. The mean hemoglobin concentration was $10.96 \pm 1.85 \mathrm{~g} / \mathrm{dL}$, males $11.08 \pm 1.85 \mathrm{~g} / \mathrm{dL}$ and females, $10.78 \pm 2.23 \mathrm{~g} / \mathrm{dL}, \mathrm{P}=0.06$. The mean hemoglobin of the participants with hypertension, CGN, CIN, obstructive uropathy, and others were $13.20 \pm$ $3.86 \mathrm{~g} / \mathrm{dL}, 13.59 \pm 4.21 \mathrm{~g} / \mathrm{dL}, 12.71 \pm 3.68$ $\mathrm{g} / \mathrm{dL}, 13.29 \pm 4.40 \mathrm{~g} / \mathrm{dL}$ and $13.20 \pm 4.03$ $\mathrm{g} / \mathrm{dL}$ respectively. The mean serum sodium was less in females, a greater proportion of women than males had hyponatremia (29.03\% versus $25.61 \%)$. Metabolic acidosis was found in $44.4 \%$ of the participants, more so in females, $\mathrm{P}=0.04$. Hypocalcemia was present in $36.80 \%$ of participants, and the mean phosphate, and calcium phosphate product ware higher in females than males $\mathrm{P}=0.03$ and $\mathrm{P}=0.05$ respectively. Calcium x Posphate product was elevated in $10.5 \%$ of the participants. The mean serum creatinine was higher in males than females, $\mathrm{P}=0.001$. (Table 3) The mean eGFR was higher in males than females, $\mathrm{P}=0.02$. The mean urine $\mathrm{ACR}$ was higher in males than females, $\mathrm{P}=1.1$. The mean length of the right kidney was less 
Uduagbamen PK et.al. Anemia of chronic kidney disease: pattern, prevalence and clinical correlates. a single center cross sectional study in South Western Nigeria.

than the left $(10.03 \pm 2.14 \mathrm{~cm}$ versus $10.53 \pm 2.06 \mathrm{~cm}), \mathrm{P}=0.06$.

Table 2: Laboratory and radiological characteristics of the participants

\begin{tabular}{|c|c|c|c|}
\hline Variables & Males & Females & P-value \\
\hline Sodium, $\mathrm{mmol} / \mathrm{L}($ mean $\pm \mathrm{SD})$ & $137.09 \pm 4.88$ & $136.18 \pm 5.00$ & 0.08 \\
\hline Potassium, $\mathrm{mmol} / \mathrm{L}($ mean $\pm \mathrm{SD})$ & $4.06 \pm 0.64$ & $4.05 \pm 0.68$ & 0.1 \\
\hline Chloride, $\mathrm{mmol} / \mathrm{L}($ mean $\pm \mathrm{SD})$ & $102.93 \pm 5.21$ & $102.48 \pm 5.32$ & 0.5 \\
\hline Bicarbonate, $\mathrm{mmol} / \mathrm{L}($ mean $\pm \mathrm{SD})$ & $21.61 \pm 3.87$ & $20.57 \pm 3.78$ & 0.05 \\
\hline Calcium, mmol/L (mean \pm SD) & $2.21 \pm 0.31$ & $2.18 \pm 0.30$ & 0.05 \\
\hline Phosphate, $\mathrm{mmol} / \mathrm{L}$ (mean \pm SD) & $1.47 \pm 0.39$ & $1.52 \pm 0.45$ & 0.04 \\
\hline Calcium $x$ phosphate, $\mathrm{mmol}^{2} / \mathrm{L}^{2}($ mean $\pm \mathrm{SD})$ & $3.22 \pm 0.85$ & $3.27 \pm 0.97$ & 0.05 \\
\hline Urea, $\mathrm{mmol} / \mathrm{L}($ mean $\pm \mathrm{SD})$ & $16.91 \pm 1.71$ & $13.96 \pm 2.56$ & 0.03 \\
\hline Creatinine, umol/L (mean \pm SD) & $135.24 \pm 11.48$ & $123 \pm 2.62$ & 0.001 \\
\hline $\mathrm{GFR}, \mathrm{ml} / \mathrm{min} / 1.73^{2}($ mean $\pm \mathrm{SD})$ & $47.33 \pm 22.86$ & $41.28 \pm 18.08$ & 0.02 \\
\hline Hemoglobin concentration $\mathrm{mg} / \mathrm{dL}$ (mean $\pm \mathrm{SD}$ ) & $11.08 \pm 1.85$ & $10.78 \pm 2.23$ & 0.06 \\
\hline Albumin, $\mathrm{mg} / \mathrm{dL}($ mean $\pm \mathrm{SD})$ & $4.59 \pm 0.51$ & $4.14 \pm 0.47$ & 0.05 \\
\hline Urine $\mathrm{ACR}, \mathrm{mg} / \mathrm{g}(\mathrm{mean} \pm \mathrm{SD})$ & $35.74 \pm 8.92$ & $35.63 \pm 8.54$ & 1.1 \\
\hline Kidney length, cm (mean \pm SD) & $10.83 \pm 2.13$ & $10.13 \pm 1.98$ & 0.06 \\
\hline Kidney cortical thickness, $\mathrm{mm}$ (mean \pm SD) & $9.34 \pm 3.15$ & $8.47 \pm 3.58$ & 0.03 \\
\hline
\end{tabular}

Table 3: Association between anemia and stages of chronic kidney disease

\begin{tabular}{|l|l|l|l|}
\hline Variables & HBC, & HBC, & P- \\
& mg/dL & mg/dL & value \\
& M: $<\mathbf{1 3 . 0 0}$ & $\mathbf{M : ~}>\mathbf{1 3 . 0 0}+$ & \\
& F: $<\mathbf{1 2 . 0 0}$ & $\mathbf{F}:>\mathbf{1 2 . 0 0}$ & \\
$\mathbf{N - 8 7}(\mathbf{\%})$ & \\
\hline CKD $\mathbf{5 7}(\mathbf{\%})$ & $5(8.77)$ & $28(32.18)$ & 0.003 \\
\hline CKD Stage 3a & $11(19.30)$ & $36(41.38)$ & \\
\hline CKD Stage 4 & $22(38.60)$ & $20(22.98)$ & \\
\hline $\begin{array}{l}\text { CKD Stage 5 (non- } \\
\text { dialytic) }\end{array}$ & $19(33.33)$ & $3(5.26)$ & \\
\hline
\end{tabular}

The severity of anemia was positively, though not uniformly related to the stage of CKD (Table 3) as, a higher percentage of participants with Stage $3 \mathrm{a}$ disease had normal HBC while a higher percentage of Stage 5 disease had anemia, $\mathrm{P}<0.001$.

HBC-hemoglobin concentration

Table 4: Association between anemia and participant' characteristics

\begin{tabular}{|c|c|c|c|c|c|}
\hline Variables & $\begin{array}{l}\text { Anemia } \\
\mathrm{N}=57(\%)\end{array}$ & $\begin{array}{l}\text { No anemia } \\
87(\%)\end{array}$ & OR & $95 \% \mathrm{CI}$ & P-value \\
\hline $\begin{array}{l}\text { Sex } \\
\text { Males } \\
\text { Females }\end{array}$ & $\begin{array}{l}34(41.46) \\
23(37.10)\end{array}$ & $\begin{array}{l}48(58.54) \\
39(62.90)\end{array}$ & 0.94 & $0.93-1.86$ & 0.06 \\
\hline $\begin{array}{l}\text { Age } \\
<60 \\
>60\end{array}$ & $\begin{array}{l}37(31.36) \\
20(76.92) \\
\end{array}$ & $\begin{array}{l}81(68.64) \\
6(23.08)\end{array}$ & 5.22 & $3.84-873$ & $<0.001$ \\
\hline $\begin{array}{l}\text { BMI } \\
<25.0 \\
>25.0\end{array}$ & $\begin{array}{l}22(37.93) \\
35(40.70) \\
\end{array}$ & $\begin{array}{l}36(62.07) \\
51(59.30) \\
\end{array}$ & 0.74 & $0.51-1.05$ & 0.2 \\
\hline $\begin{array}{l}\text { Systolic BP } \\
<140 \\
>140\end{array}$ & $\begin{array}{l}19(21.35) \\
38(69.09) \\
\end{array}$ & $\begin{array}{l}70(78.65) \\
17(30.91)\end{array}$ & 3.38 & $1.83-4.74$ & 0.003 \\
\hline $\begin{array}{l}\text { Diastolic BP } \\
<90 \\
>90 \\
\end{array}$ & $\begin{array}{l}28(32.18) \\
29(50.88) \\
\end{array}$ & $\begin{array}{l}59(67.82) \\
28(49.12) \\
\end{array}$ & 2.54 & $2.27-4.38$ & 0.03 \\
\hline $\begin{array}{l}\text { Bicarbonate, } \mathbf{~ m m o l} / \mathbf{L} \\
<22.0 \\
>22.0 \\
\end{array}$ & $\begin{array}{l}40(50.00) \\
17(26.56) \\
\end{array}$ & $\begin{array}{l}40(50.00) \\
47(73.44) \\
\end{array}$ & 3.02 & $1.84-4.15$ & 0.004 \\
\hline $\begin{array}{l}\text { Anion gap, mEq } \\
<16 \\
>16 \\
\end{array}$ & $\begin{array}{l}19(21.11) \\
38(70.37)\end{array}$ & $\begin{array}{l}71(78.89) \\
16(29.63) \\
\end{array}$ & 3.11 & $2.04-4.88$ & 0.003 \\
\hline $\begin{array}{l}\text { eGFR, } \mathbf{~ m l} / \mathbf{m i n} \\
<45 \\
>45 \\
\end{array}$ & $\begin{array}{l}48(43.24) \\
9(27.28) \\
\end{array}$ & $\begin{array}{l}63(56.76) \\
24(72.72) \\
\end{array}$ & $3-32$ & $1.94-4.96$ & 0.001 \\
\hline $\begin{array}{l}\text { Albumin, } \mathbf{~ m g / d L ~} \\
<35.0 \\
>35.0 \\
\end{array}$ & $\begin{array}{l}8(88.89) \\
49(36.30) \\
\end{array}$ & $\begin{array}{l}1(11.11) \\
86(63.70)\end{array}$ & 5.85 & $3.62-7.27$ & $<0.001$ \\
\hline $\begin{array}{l}\text { Urine ACR, } \mathbf{~ m g / g} \\
<30 \\
>30\end{array}$ & $\begin{array}{l}17(19.77) \\
50(73.53) \\
\end{array}$ & $\begin{array}{l}69(80.23) \\
18(26.47) \\
\end{array}$ & $5-57$ & $2.89-6.51$ & $<0.001$ \\
\hline $\begin{array}{l}\text { Mean kidney length } \\
<9 \\
>9.0\end{array}$ & $\begin{array}{l}23(65.71) \\
34(31.19)\end{array}$ & $\begin{array}{l}12(34.29) \\
75(68.81) \\
\end{array}$ & 2.75 & $2.21-4.55$ & 0.003 \\
\hline
\end{tabular}


Univariate analysis (Table 4) showed participants age, blood pressure, bicarbonate, anion gap, eGFR, serum albumin, urine albumin creatinine ratio and mean kidney length as independent associates of anemia.

Multiple regression analysis (Table 5) showed age, estimated glomerular filtration rate, serum albumin and urine ACR as independent predictors of anemia.

Table 5: Multivariate regression analysis

Table 5: Multivariate regression analysis
\begin{tabular}{|l|l|l|l|}
\hline Variables & aOR & $\mathbf{9 5 \%}$ CI & $\begin{array}{l}\text { P- } \\
\text { value }\end{array}$ \\
\hline Age & 6.94 & $2.04-13.86$ & $<0.001$ \\
\hline Systolic blood pressure & 1.02 & $0.88-1.06$ & 0.09 \\
\hline Bicarbonate glomerular & 1.2 & $1.08-2.97$ & 0.05 \\
\hline Anion gap & 1.0 & $0.85-1.69$ & 0.07 \\
\hline $\begin{array}{l}\text { Estimated } \\
\text { filtration rate }\end{array}$ & $1.33-3.06$ & 0.03 \\
\hline Albumin & 6.02 & $4.82-11.35$ & $<0.001$ \\
\hline Urine albumin creatinine ratio & 5.92 & $3.64-9.77$ & $<0.001$ \\
\hline Kidney length & 0.99 & $0.37-1.34$ & 0.4 \\
\hline $\begin{array}{l}\text { aOR-adjusted odds ratio, CI-95\% confidence interval, } \\
\text { estimated glomerular filtration- } \\
\text { ratio. }\end{array}$
\end{tabular}

\section{DISCUSSION}

We found in this cross sectional study a prevalence of $39.6 \%$ of anemia, with $37.80 \%$ in males and $41.93 \%$ in females. A negative relationship was found between the HBC and the stages of CKD. We also found in this study that the predictors of anemia in predialysis CKD were age, glomerular filtration rate, serum albumin and urine albumin creatinine ratio. The prevalence of anemia in this study is similar to the $43.1 \%$ reported by Nalado et $\mathrm{al}^{26}$ in a study involving blacks and white South Africans. It is very much higher than the $20.6 \%$ and $18.2 \%$ found by Awan et al, ${ }^{27}$ and Portoles et $\mathrm{al}^{28}$ in an Indian/Asian population. Our prevalence is however much lower than the $75-79 \%$ found in some low and medium income nations of Africa and Asian. ${ }^{8-10}$ Apart from differences in methodological procedure, differences in the diagnostic cutoff values may also play some part.

The relationship between the hemoglobin concentration and the stage of CKD depicted a positive pattern in our study. This is in agreement with Alagoz et $\mathrm{al}^{29}$ and other authors who reported positive relationship between anemia severity and the stage of CKD. ${ }^{30}$ Silverberg et $\mathrm{al}^{31}$ and Nalado in separate studies, however found alteration in the known "sliding scale like descend" of the HBC as CKD progresses. Anemia is commonly reported from CKD stage 3 disease. The institution of iron supplementation, initially in oral forms, couple with an exaggerated compensatory response from the erythropoiesis stimulating sites and chemical substances can lead to raised $\mathrm{HBC}$ even with declining kidney function. It is reported that anemia treatment in CKD results in improvements in both the laboratory and clinical profile in the immediate, short term and long term outcome. However, in LINs, optimal therapy is not commonly achieved, as observed in our cohorts with stage 5 disease who were receiving ESAs.

In our study, males were less likely to be anemic compared to females and this mirrors findings from a previous study. More than a third of females in our study were in their active reproductive years, the monthly blood loss would have been expected to contribute to the higher incidence of anemia in them but the fact that most of these women were not taking an ACEI or an ARB that are known to inhibit erythropoiesis. ${ }^{32}$ unlike the men tended to neutralize the contribution of women' monthly flow to anemia. The erythropoiesis enhancing actions of androgens in males could also contribute to the higher HBC in males. ${ }^{33}$

We found a negative relationship between the HBC and age as previously reported. ${ }^{34}$ The renal function decline with aging (physiologic or pathologic) coupled with physiologic reductions in androgen, necessitates an accompanying reduction in erythropoiesis. The negative relationship between the HBC and the BMI in our study mirrors findings by Zhao et al. ${ }^{35}$ The fact that majority of our cohorts were not in ESRD, could have explain this. as obesity is known to portray a better prognosis in CKD. It would have been expected that higher BMI entails better nutrition and higher serum albumin, which in this study had a 
positive relationship with $\mathrm{HBC}$, but the bimodal levels of albumin in inflammation (common in CKD) and in optimal nutrition, makes conclusive assertions difficult without involving other markers of inflammation. ${ }^{36}$ The negative association between HBC and blood pressure in CKD is well reported. The incidence of left ventricular hypertrophy (LVH) and anemia that complicate CKD are known to be concurrent events in a cause and effect relationship. Anemia induces cardiac enlargement and LVH in CKD. Progression of LVH could lead to heart failure which worsens the fluid retention, increases plasma volume causing hemodilution and worsening red cell indexes. ${ }^{16}$

The higher incidence of anemia in CIN compared to other etiologic factors agrees with findings from a previous study. The affectation of the fibroblast cells of the peritubular interstitium (site of erythropoiesis) in CIN makes anemia a very common finding in them, often times, anemia becoming out of proportion to the stage of $\mathrm{CKD} .^{37,}, 38$ The rising trend of the use of weight reducing (slimming) substances which could lead to CIN may also contribute to the higher incidence of renal anemia in CIN. ${ }^{39}$ The higher prevalence of anemia in stage 5 than stage 4 disease despite the use of ESAs in stage 5 agrees with previous findings. ${ }^{4}$ Suboptimal anemia correction in ESRD is commonly attributed to poor access to these drugs on account of the cost and infection and other inflammatory conditions that become more prevalent as kidney function decline.

The higher phosphate in females in this studies mirrors findings by Onufrak et al. ${ }^{40}$ But disagrees with previous studies that reported the reverse. In our clime, males commonly take more animal protein, particularly meat, than women and so are expected to have higher serum values. This finding may give credence to the fact that phosphate retention results more from low excretion than increased intake considering the fact that women had lower eGFR than men.
The positive relationship between the severities of anemia and metabolic acidosis agrees with previous findings as Moranne et $\mathrm{al}^{41}$ had reported the time course of the emergence and progression of features of CKD in relation to the GFR decline. The development of hyperparathyroidism herald metabolic acidosis and anemia in CKD. Though we didn't seek to assess the parathyroid hormone and CKD bone mineral disease (CKD-BMD) in this study, the higher phosphate, and Calcium Phosphate Product in addition to low bicarbonate and elevated anion gap in cohorts further confirms these associations in CKD. ${ }^{12}$

We found a positive relationship between serum albumin and the HBC and this is in agreement with finding from other studies. Hypoalbuminemia induces a stimulatory effect on the anti-diuretic hormone $(\mathrm{ADH})$. The resulting poor salt water retention could lead to plasma dilution and hyponatremia. Although, plasma dilution would have lesser implication on the HBC compared with the hematocrit, the hemodilution it induces could give falsely low red blood cell indices, ${ }^{42}$

Some limitations encountered in this study included our inability to do a complete panel of iron studies. Been a cross sectional study, in design, a reassessment of variables was not done hence possible variation could have been missed. Other indices of nutrition like folate and Vitamin $\mathrm{B}_{12}$ were not assayed. We didn't seek to assess participants for CKD-BMD hence the parathyroid was not assessed. The strength of the study is hinged on detailed history concerning the etiology of CKD, use of exogenous nephrotoxins (NSAIDs, slimming drugs and herbal remedies), albuminuria testing and the assessment of drugs with effects on erythropoiesis.

\section{CONCLUSION}

Anemia in CKD results primarily from reduced renal erythropoietin production and is very common, with a prevalence of $39.58 \%$ in our study. It was 
commoner in females, positively associated with age, the BMI and blood pressure, urine ACR and metabolic acidosis. Anemia was negatively correlated with serum albumin. Determinants of renal anemia were age, obesity, kidney function and female gender. Independent predictors of renal anemia were increasing age, stage 5 CKD, hypoalbuminemia and urine ACR. Improvement in kidney function, early and continuous assessment of the red cell indices couple with constant review of prescribed and non-prescribed drugs would be needed in CKD to minimize the various complications associated with renal anemia.

\section{ACKNOWLEDGEMENT}

We thank the nurses, laboratory and other supporting staffs of the hospital for their contribution towards the success of the study.

\section{Conflict Of Interest: None declared}

\section{Funding: None}

\section{Ethical Approval: Approved}

\section{REFERENCES}

1. McClellan WM, Flanders WD, Langston RD, Jurkovitz C, Presley R. Anemia and renal insufficiency are independent risk factors for death among patients with congestive heart failure admitted to community hospitals: a population-based study. J Am Soc Nephrol. 2002; 13(7): 1928-36.

2. Collins AJ, Li S, Peter WS, Ebben J, Roberts T, Ma JZ, Manning W. Death, hospitalization, and economic associations among incident hemodialysis patients with hematocrit values of 36 to 39\%. J Am Soc Nephrol. 2001; 12(11): 2465-2473.

3. KDIGO Anemia Work Group KDIGO clinical practice guideline for anemia in chronic kidney disease. Kidney Int Suppl. 2012; 2: S279-S335

4. Eriksen BO, Ingebretsen OC: The progression of chronic kidney disease: A 10-year population-based study of the effects of gender and age. Kidney Int 69: 375-382, 2006
5. Locatelli F, Bárány P, Covic A et al. ERAEDTA ERBP Advisory Board. Kidney Disease: Improving Global Outcomes guidelines on anaemia management in chronic kidney disease: a European Renal Best Practice position statement. Nephrol Dial Transplant. 2013; 28: 1346-1359

6. Macdougall IC. Intravenous iron therapy in patients with chronic kidney disease: recent evidence and future directions. Clin Kidney J. 2017; 10(Suppl 1):i16-i24.

7. Wetmore JB, Li S, Yan H, Xu H, Peng Y, Sinsakul MV, et al. Predialysis anemia management and outcomes following dialysis initiation: A retrospective cohort analysis. PLoS One 2018; 26:13(9):1-14

8. Visser J, Herselman M, Janicker Visser MH. Anaemia in South Africa: the past, the present and the future. South Afr J Clin Nutr. 2013; 26(4):166-1679.

9. Chinwuba Ijoma IU, Ijoma U. High prevalence of anemia in predialysis patients in Enugu, Nigeria. Nephrol Rev. 2010; 2(14):5.

10. Shaheen FA, Souqiyyeh MZ, Al-Attar BA, et al. Prevalence of anemia in predialysis chronic kidney disease patients. Saudi $J$ Kidney Dis Transpl. 2011; 22(3): 456-463.

11. Hanna RM, Streja E, Kamyar KalantarZadeh Burden of Anemia in Chronic Kidney Disease: Beyond Erythropoietin Adv Ther 2021; 38(1): 52-75 doi: 10.1007/s12325020-01524-6

12. National Kidney Foundation. (2012) KDOQI Clinical Practice Guideline for Diabetes and CKD: 2012 update. Am J Kidney Dis. 60, 850-886 doi.org/10.1053/j.ajkd.2012.07.005

13. Levey AS, Stevens LA, Schmid CH, Zhang YL, AFr C, Feldman HI, et al. (2009) A new equation to estimate glomerular filtration rate. Ann Intern Med. 150, 60412. https://doi.org/10.7326/0003-4819-1509-200905050-00006

14. Lamb EJ, MacKenzie E, Stevens PE. How should proteinuria be measured. Ann Clin Biochem 2009; 46: 3205-217

15. Declaration of Helsinki 2000. World Medical Association [cited 2020 Apr 29]. Available from: https://www.wma.net/whatwe-do/ medical-ethics/declaration-ofhelsinki/doh-oct2000/.

16. Thomas Unger T, Claudio Borghi $\mathrm{C}$, Charchar F, et al. 2020 International Society of Hypertension Global 
Uduagbamen PK et.al. Anemia of chronic kidney disease: pattern, prevalence and clinical correlates. a single center cross sectional study in South Western Nigeria.

Hypertension Practice Guidelines Hypertension. 2020; 75:1334-1357

17. National Kidney Foundation. (2012) KDOQI Clinical Practice Guideline for Diabetes and CKD: 2012 update. Am J Kidney Dis. 60, 850-886 https://doi.org/10.1053/j.ajkd.2012.07.005

18. Cappellini MD, Motta I. Anemia in Clinical Practice-Definition and Classification: Does Hemoglobin Change With Aging? Semin Hamatol 2015; 52(4): 261-9 doi: 10.1053/j.seminhematol.2015.07.006

19. Kim S, McClave SA, Martindale RG, Miller KR, Hurt RT. (2017) Hypoalbuminemia and Clinical Outcomes: What is the Mechanism behind the Relationship? Am Surg 83 12201227

$10.1177 / 000313481708301123$

20. Uduagbamen PK, Sanusi M, Udom OB, Salami OF, Adebajo AD, Alao OJ. Preoperative Metabolic Acidosis in a Cardiovascular Surgical Intensive Care Unit: Risk factors, Clinical Correlates and Outcome. WJCS 2020; 10(11): 226-241 doi: 10.4236/wjcs.2020.1011025

21. Uduagbamen PK, Hamzat MA Ehioghae O. Urinary Assessment among Nigerians in Health and with Frequent Use of Nonsteroidal Anti-inflammatory Drugs. RJ Health Sci 2020; 8(4): 255-233.

22. Boag AM, Breheny C, Handel I, Gow AG. Evaluation of the effect of urine dip vs urine drip on multi-test strip results. Et Clin Pathol 2019; 48, 276281.https://doi.org/10.1111/vcp.12730

23. Third Report of the National Cholesterol Education Program (NCEP) Expert panel on detection, evaluation, and treatment of high blood cholesterol in adults (adult treatment panel III) (2002) Final report. Circulation. 106, 3143-421. https://doi.org/10.1161/circ.106.25.3143

24. Emamian SA, Nielsen MB, Pedersen JF, et al. (1993) Kidney dimensions at sonography: Correlation with age, sex, and habitus in 665 adult volunteers. AJR Am J Roentgenol 193;160, 83-86 https://doi.org/10.2214/ajr.160.1.8416654

25. Hosmer DW, Lameshow S. Applied Logistic Regression. 2nd ed. Wiley: New York N.Y.; 2000. p. 95.

26. Nalado AM, Mahlangu JN, Waziri B et al. Ethnic prevalence of anemia and predictors of anemia among chronic kidney disease patients at a tertiary hospital in
Johannesburg, South Africa Intl J Nephrol

Renovasc 2019; 12:19-32
doi: 10.2147/JJNRD.S179802

27. Awan AA, Walther CP, Richardson PA, et al. Prevalence, correlates and outcomes of absolute and functional iron deficiency anemia in nondialysis-dependent chronic kidney disease Nephrol Dial Transplant 2021; 36(1): 129-136 DOI: $10.1093 /$ ndt/gfz192

28. Portolés J, Gorriz JL, Rubio E. The development of anemia is associated to poor prognosis in $\mathrm{NKF} / \mathrm{KDOQI}$ stage 3 chronic kidney disease BMC Nephrol 2013; 14, 22019; 18(12): 19-32.

29. Alagoz S, Mevlut TD, Necmi E et al. Prevalence of anemia in predialysis chronic kidney disease: Is the study center a significant factor? doi.org/10.1371/journal.pone.0230980

30. Hill NR, Fatoba ST, Oke JL, et al. Global prevalence of chronic kidney disease - a systematic review and meta-analysis. PLoS ONE, 11 (2016), pp. e0158765 doi.org/10.1371/journal.pone.0158765

31. Silverberg DS, Wexler D, Iaina A, Schwartz D. The correction of anemia in patients with the combination of chronic kidney disease and congestive heart failure may prevent progression of both conditions. Clin Exp Nephrol. 2009; 13(2): 101-106.

32. Mrug M, Stopka T, Julian B.A. et al. Angiotensin II stimulates proliferation of normal early erythroid progenitors. J Clin Invest. 2000; 100: 2310-2314

33. Shahani S, M Braga-Basaria M,, M Maggio $\mathrm{M}$, et al. Androgens and erythropoiesis: past and present J Endocrinol Invest 2009; 32(8): 704-16 DOI: 10.1007/BF03345745

34. Liu H, Ye Y, Chen Y, et al. Therapeutic targets for the anemia of predialysis chronic kidney disease: a meta-analysis of randomized, controlled trials. J Investig Med 2019; 67(6):1002-1008. pmid:30755495

35. Zhao L ,Zhang X, Shen Y ,Fang X, Wang Y, Wang F. Obesity and iron deficiency: a quantitative meta-analysis.Obesity/Nutrition 2015; $16(12)$ : $1081-1093$ https://doi.org/10.1111/obr.12323

36. McClellan W, Aronoff SL, Bolton WK, et al. The prevalence of anemia in patients with chronic kidney disease Curr Med Res Opin 2004; 20(9): 1501-10 DOI: $10.1185 / 030079904 X 2763$ 
Uduagbamen PK et.al. Anemia of chronic kidney disease: pattern, prevalence and clinical correlates. a single center cross sectional study in South Western Nigeria.

37. De Broe, M.E. and Elseviers, M.M. (2009) Over-the-Counter Analgesic Use. Journal of the American Society of Nephrology , 20, 2098-2103.

doi.org/10.1681/ASN.2008101097

38. Uduagbamen PK, Salako BL, Hamzat MA, et al. Kidney Function in Frequent Users of Non-steroidal anti-inflammatory Drugs (NSAIDs) Open J Int Med 2020; 10(1): 6982

39. Oreagba IB, Oshikoya KA, Amachree M. Herbal medicine use among urban residents in Lagos, Nigeria BMC Complement Altern Med. 2011; 11: 117.doi: 10.1186/14726882-11-117

40. Onufrak SJ, Bellasi A, Cardarelli F, et al. Investigation of Gender Heterogeneity in the Associations of Serum Phosphorus With
Incident Coronary Artery Disease and AllCause Mortality Am J Epidemiol 2009 Jan 1; 169(1): 67-77. doi: 10.1093/aje/kwn285

41. Moranne O, Froissart M, Rossert J, et al . Timing of Onset of CKD-Related Metabolic Complications. JASN 2009; 20(1): 164-171. doi.org/10.1681/ASN.2008101097

42. Tanemoto M. Progression of metabolic acidosis in chronic kidney disease. Kidney Dis. 2020; 6(1):59-64

How to cite this article: Uduagbamen PK, Oyelese AT, Alalade BA et.al. Anemia of chronic kidney disease: pattern, prevalence and clinical correlates. a single center cross sectional study in South Western Nigeria. Int J Health Sci Res. 2021; 11(10): 250-259. DOI: https://doi. org/10.52403/ijhsr.20211033 